\section{RMD Open}

Rheumatic \&

Musculoskeletal Diseases

\title{
Does autoimmune thyroid disease affect rheumatoid arthritis disease activity or response to methotrexate?
}

\author{
Kristin Waldenlind (D), ${ }^{1,2}$ Bénédicte Delcoigne, ${ }^{1}$ Saedis Saevarsdottir, ${ }^{1,3}$ \\ Johan Askling ${ }^{1,2}$
}

To cite: Waldenlind $\mathrm{K}$, Delcoigne B, Saevarsdottir S, et al. Does autoimmune thyroid disease affect rheumatoid arthritis disease activity or response to methotrexate? RMD Open 2020;6: 001282. doi:10.1136/rmdopen-2020001282

- Additional material is published online only. To view please visit the journal online (http://dx.doi.org/10.1136/rmdo pen-2020-001282).

Received 21 April 2020 Revised 1 June 2020

Accepted 25 June 2020
Check for updates

(c) Author(s) (or their employer(s)) 2020. Re-use permitted under CC BY-NC. No commercial re-use. See rights and permissions. Published by BMJ.

For numbered affiliations see end of article.

\section{Correspondence to}

Kristin Waldenlind;

kristin.waldenlind@ki.se

\section{ABSTRACT}

Objective To investigate if autoimmune thyroid disease (AITD) impacts rheumatoid arthritis (RA) disease activity or response to methotrexate.

Methods A nationwide register-based cohort study of 9 004 patients with new-onset RA from the Swedish Rheumatology Quality Register year 2006-2016, with linkage to other nationwide registers to identify comorbidity with AITD defined as thyroxine prescription before RA diagnosis, excluding non-autoimmune causes. We compared RA disease activity using 28-joint Disease Activity Score (DAS28) and its components, and EULAR response, between patients with and without AITD, using logistic regression.

Results At diagnosis, patient reported outcome measures (PROMs; patient global, Health Assessment Questionnaire Disability Index and pain) but not objective disease activity measures (erythrocyte sedimentation rate and swollen joint count) were significantly higher ( $p<0.05$ for all PROMs) among RA patients with AITD compared with those without. The level of DAS28 was 5.2 vs 5.1 . By contrast, AITD had little influence on EULAR response to methotrexate at 3 months (OR of non/moderate response $=0.95,95 \% \mathrm{Cl} 0.8$ to $1.1)$, nor at 6 months. When stratified by age, however, AITD was more common among EULAR non/moderate responders at 3 and 6 months in patients below 45 years resulting in ORs of non/moderate response of 1.44 (0.76-2.76) and 2.75 (1.04-7.28).

Conclusion At diagnosis, RA patients with concomitant AITD score worse on patient reported but not on objective RA disease activity measures, while DAS28 was only marginally elevated. The overall chance of achieving a EULAR good response at 3 or 6 months remains unaffected, although among a limited subgroup of younger patients, AITD may be a predictor for an inferior primary response.

\section{INTRODUCTION}

Autoimmune thyroid disease (AITD), including hypothyroidism and hyperthyroidism of autoimmune origin, is the most common autoimmune disease in the general population, with a prevalence of approximately $5 \%{ }^{1}$ The prevalence of AITD is increased in patients with rheumatoid arthritis (RA),

\section{Key messages}

What is already known about this subject?

- Autoimmune thyroid disease (AITD) increases the risk of RA. With a prevalence of approximately $10 \%$, AITD is also one of the most common comorbid conditions in patients with RA. Yet, it is less well understood whether AITD affects also the RA phenotype and response to anti-rheumatic therapies.

\section{What does this study add?}

- In this Swedish cohort study of early RA patients, the disease activity and treatment response to methotrexate as first-line therapy was compared between patients with early RA and AITD vs RA patients without this comorbidity.

- AITD, present among $11 \%$ of all the patients with RA, was linked to worse subjective but not to worse objective measures of RA disease activity. However, AITD did not impact response to treatment, with one exception, young patients with both RA and AITD, who were less likely to achieve a good response to methotrexate.

How might this impact on clinical practice?

- Through worse subjective RA disease activity components, concomitant AITD influences the phenotypic presentation of RA and the observed composite treatment response measures used in clinical practice.

- When treating and evaluating early RA patients with concomitant AITD, it is of importance to pay attention not only to the overall disease activity and response measures such as DAS28, but to unpick its components. 
In contrast to the well-established increased occurrence of RA in patients with AITD ${ }^{10-12}$ and increased occurrence of AITD in patients with RA, ${ }^{12} 13$ considerably less is known about the impact of AITD on the phenotypic presentation of RA, and on its impact on response to antirheumatic therapies. Previous findings indicate an association between hypothyroidism and higher macrophage inflammatory response with release of pro-inflammatory cytokines (interleukin-1 (IL-1), IL-6 and tumour necrosis factor- $\alpha) .{ }^{1415}$ Hypothyroidism may cause symptoms such as fatigue, myalgia and arthralgia that may also occur in RA. ${ }^{16}$ One study, of 52 prevalent RA patients, reported a correlation between hypothyroidism and higher disease activity. ${ }^{17}$ Another study, based on 439 prevalent RA patients from a Danish registry and based on 28-joint Disease Activity Score-C reactiveprotein (DAS28-CRP) scores reported, somewhat contradictory, no significant difference in RA disease activity at diagnosis but a reduced chance of response to anti-rheumatic drugs at 4 months from treatment initiation. ${ }^{18}$ These findings call for a more detailed assessment of how AITD impacts the presentation and evolution of RA disease activity, as measured by different types of metrics, and also of how AITD affects the observed RA treatment response.

The objectives of this study were therefore to investigate, in a study population large enough to allow for assessments of differences across subgroups of patients, whether and how concomitant AITD impacts patientrelated and physician-related measures of disease activity, at the time of RA diagnosis and at 3-month and 6-month follow-up visits, and also how AITD affects the response to first-line treatment with methotrexate. In addition to overall effects, we investigated variations in RA disease presentation and treatment response across subsets as defined by RA serological status, sex and age.

\section{PATIENTS AND METHODS}

\section{Setting and data sources}

The setting and data sources used for this study have been described in detail previously. ${ }^{19}$ Following RA diagnosis, the majority of Swedish RA patients start methotrexate as their first disease-modifying anti-rheumatic drugs (DMARD). The dose of methotrexate is increased up to $20 \mathrm{mg}$ per week. Patients are followed-up according to an early RA treatment guideline (see eText 1 in online sup plementary material). In brief, we used data from the following data sources: The Swedish Rheumatology Quality Register (SRQ) is a nationwide clinical register of patients with RA. It is used in clinical practice since 1996 to follow patients' disease course longitudinally, including antirheumatic treatments, health-related variables and the physicians and patients' assessment of disease activity. The current coverage is close to $90 \%$ of all new-onset RA. To be registered as 'early RA' in the SRQ, the patient must fulfill the American College of Rheumatology criteria for $\mathrm{RA}^{20}$ and/or the American College of Rheumatology/European League Against Rheumatism classification criteria $^{21}$ with a RA symptom duration less than 12 months. The Swedish prescribed drug register (PDR) started in 2005 and includes information on all dispensations of prescribed drugs in Sweden. The Swedish cancer register started in 1958 and includes all incident diagnoses of cancer and is mandatory for all clinicians.

Swedish residents are assigned a personal identification number, unique for each individual, which enables linkage of individual-level data across nationwide registers, and the current study is based on a linkage between the registers described above. The Stockholm Regional Ethics Committee approved this study (DNR 2015/1844-31/2).

\section{Study population}

We identified all patients included as early RA in the SRQ between January 1, 2006 and December 31, 2016 ( $\mathrm{n}=13$ 187). The current analyses are based on those 9004 patients (6 072 women and 2932 men; mean \pm SD age, $65.8 \pm 15.0$ years) who started methotrexate monotherapy at diagnosis and who had disease activity measures registered both at start and at follow-up visits to allow for response analyses, see table 1 and online supplementary figure 1. The occurrence of AITD among excluded patients did not differ substantially from those included.

\section{Occurrence of AITD}

The vast majority of patients treated with thyroxine substitution have an underlying AITD, once nonautoimmune causes for treatment are excluded. ${ }^{19} 2223$ We therefore defined AITD as filling a prescription of thyroid hormone substitution therapy, identified through linkage to the PDR 2005 through 2016. Patients with a prescription of iodine-containing drugs (interferon-alpha, lithium and amiodarone) or a previous thyroid cancer, based on linkage to the PDR and the Swedish Cancer Register were excluded (see eText 2 for the ATC and ICD codes used and online supplemen tary figure 1). Prevalent AITD was defined as a thyroxine prescription in the PDR already before the diagnosis of RA.

\section{RA disease activity and treatment response}

We used DAS28-erythrocyte sedimentation rate (ESR) to define RA disease activity and the change in RA disease activity between visits, $\triangle \mathrm{DAS28}$-ESR, at the 3-month or 6 -month visit after treatment start ( $\pm 1-2$ months). If the patient had several visits during the specified time period, we used the visit closest to 3 and 6 months from the time of diagnosis, respectively.

Response states were defined as non, moderate and good responder based on the EULAR DAS28-ESR response criteria. ${ }^{24}$ In addition, a patient was defined as non-responder if switching from methotrexate to another DMARD at or before the follow-up visit, irrespective of EULAR response status. Below, DAS28-ESR will be referred to as DAS28.

In addition to the patient global Visual Analogue Scale (VAS) (below referred to as 'patient global'), we used the 
Table 1 Baseline characteristics of 9004 RA patients identified in the Swedish Rheumatology Quality Register (SRQ), 2006-2016*

\begin{tabular}{|c|c|c|c|}
\hline Characteristics & $\begin{array}{l}\text { Overall } \\
(n=9 \\
004)\end{array}$ & $\begin{array}{l}\text { AITD+† } \\
(n=1 \\
003)\end{array}$ & $\begin{array}{l}\text { AITD-† } \\
(n=8 \\
001)\end{array}$ \\
\hline \multicolumn{4}{|l|}{ Sex } \\
\hline Women & $\begin{array}{l}6072 \\
(67.4)\end{array}$ & $\begin{array}{l}886 \\
(88.3)\end{array}$ & $\begin{array}{l}5186 \\
(64.8)\end{array}$ \\
\hline Men & $\begin{array}{l}2932 \\
(32.6)\end{array}$ & $\begin{array}{l}117 \\
(11.7)\end{array}$ & $\begin{array}{l}2815 \\
(35.2)\end{array}$ \\
\hline $\begin{array}{l}\text { Age at inclusion in SRQ/ } \\
\text { index date } \neq\end{array}$ & $\begin{array}{l}65.8 \\
(15.0)\end{array}$ & $\begin{array}{l}68.3 \\
(14.1)\end{array}$ & $\begin{array}{l}65.5 \\
(15.1)\end{array}$ \\
\hline \multicolumn{4}{|l|}{ RA diagnosis $\S$} \\
\hline Seropositive RA & $\begin{array}{l}6088 \\
(67.6)\end{array}$ & $\begin{array}{l}694 \\
(69.2)\end{array}$ & $\begin{array}{l}5394 \\
(67.4)\end{array}$ \\
\hline Seronegative $\mathrm{RA}$ & $\begin{array}{l}2687 \\
(29.8)\end{array}$ & $\begin{array}{l}272 \\
(27.1)\end{array}$ & $\begin{array}{l}2415 \\
(30.2)\end{array}$ \\
\hline Unspecified RA & $229(2.5)$ & $37(3.7)$ & $192(2.4)$ \\
\hline $\begin{array}{l}\text { Duration of symptoms } \\
\text { (months) }\end{array}$ & $5.5(3.3)$ & 5.5 (3.3) & $5.5(3.3)$ \\
\hline \multicolumn{4}{|l|}{ Year of inclusion in SRQ } \\
\hline 2006 & $690(7.7)$ & $68(6.8)$ & $622(7.8)$ \\
\hline 2007 & $699(7.8)$ & $65(6.5)$ & $634(7.9)$ \\
\hline 2008 & 747 (8.3) & $81(8.1)$ & $666(8.3)$ \\
\hline 2009 & $\begin{array}{l}914 \\
(10.2)\end{array}$ & $89(8.9)$ & $\begin{array}{l}825 \\
(10.3)\end{array}$ \\
\hline 2010 & $812(9.0)$ & $94(9.4)$ & $718(9.0)$ \\
\hline 2011 & $835(9.3)$ & $94(9.4)$ & $741(9.3)$ \\
\hline 2012 & $891(9.9)$ & $\begin{array}{l}113 \\
(11.3)\end{array}$ & $778(9.7)$ \\
\hline 2013 & $872(9.7)$ & $\begin{array}{l}102 \\
(10.2)\end{array}$ & $770(9.6)$ \\
\hline 2014 & $834(9.3)$ & $95(9.5)$ & $739(9.2)$ \\
\hline 2015 & $846(9.4)$ & $92(9.2)$ & $754(9.4)$ \\
\hline 2016 & $864(9.6)$ & $\begin{array}{l}110 \\
(11.0)\end{array}$ & $754(9.4)$ \\
\hline
\end{tabular}

*Values are the number (\%).

†First thyroxine prescription before RA diagnosis. Nonautoimmune cause for thyroxine prescription not excluded. $\ddagger$ Mean ( \pm SD years).

$\S$ According to the ICD 10 registered, assessed at the time of inclusion in the SRQ.

AITD, autoimmune thyroid disease; RA, rheumatoid arthritis.

following patient-reported disease activity variables: Health Assessment Questionnaire Disability Index (HAQ) and VAS pain (referred to as 'pain'). ${ }^{25}$

\section{Statistical methods}

We first examined the association between prevalent AITD and RA disease activity at diagnosis (measured as DAS28, its individual components, HAQ and pain) using linear regression adjusted for sex and age.

Second, for each RA disease activity measure, we examined the association between prevalent AITD and the change (delta) of the parameter between the RA diagnosis and the 3-month and 6-month, follow-up visits, respectively, using linear regression, with models adjusted for age and sex, as well as additionally adjusted for the baseline value of the parameter in question.

Third, we examined the association between AITD and response to methotrexate after 3 and 6 months from treatment initiation by comparing the proportions of EULAR DAS28 good responders versus moderate or nonresponders, using logistic regression adjusted for age and sex. In additional models, we also adjusted for HAQ, use of oral steroids and smoking.

All analyses were performed by using SAS version 9.4 (SAS Institute).

Because of missing values (approximately 20\%, see eText 3 in online supplementary material) on the DAS28 variables, we performed two separate analyses, one for all patients with a 3-month and/or 6-month visit $(\mathrm{n}=6025$ and $\mathrm{n}=4$ 996) and one for the patients with complete information on DAS28 variables at the same time points $(n=4831$ and $n=4010$; online supplementary figure 1 ). The proportions of patients receiving methotrexate or prednisolone at start and 3/6 months and response status were similar for the patients with versus without complete information on DAS28. The characteristics of patients with complete information on DAS28 are shown in table 2. We further imputed response status for those patients who had missing information on EULAR DAS28 response by multiple imputations (see eText 3 in online supplementary mate rial). We similarly imputed data on HAQ and smoking.

\section{RESULTS}

Among the 9004 RA patients who were included in the study, the prevalence of AITD was $11 \% \quad(n=1003)$ (table 1). As expected, the proportion of women was higher in patients with AITD compared with those without $(88 \%$ vs $65 \%)$, while the mean \pm SD age did not differ substantially between the groups ( $68 \pm 14$ vs $65 \pm 15$ years).

\section{AITD and its association with disease activity at RA diagnosis} and at $3 / 6$ months

At RA diagnosis, the patient-reported disease activity measures (patient global, HAQ and pain) were significantly higher among RA patients with AITD compared with those without: patient global 57 vs 52 , mean difference +3.6 , HAQ 1.2 vs 1.0 , mean difference +0.08 , pain 58 vs 53 , mean difference +3.8 . The DAS28 levels were clinically and statistically similar in patients with versus without AITD (5.2 vs 5.1 , mean difference +0.1 ), see table 3 . Among the individual DAS28 components, ESR, swollen joint count and tender joint count were not statistically higher in patients with versus without AITD, table 3 . At 3 and 6 months, there were only small numerical and no statistical differences in all of the above measures between patients with versus without AITD (table 3 and online appendix table I). 
Table 2 Characteristics of RA -patients identified in the Swedish Rheumatology Quality Register (SRQ), at baseline, 3-month and 6-month follow-up visit*

Patients with complete information at 3-month Patients with complete information at 6-month follow-up visit ( $n=4$ 831)

\begin{tabular}{llllll} 
& Baseline & 3-Month follow-up & & Baseline & 6-Month follow-up \\
\hline Methotrexate & $4831(100)$ & $4497(93)$ & $4010(100)$ & $3579(89)$ \\
Prednisolone & $3144(65)$ & $2984(62)$ & $2604(65)$ & $2311(58)$ \\
Response status $\dagger$ & & & & $1576(39)$ \\
$\quad$ Non-responders & & $1382(29)$ & & $776(19)$ \\
\multicolumn{2}{l}{$\begin{array}{l}\text { Moderate responders } \\
\text { Good responders }\end{array}$} & $2164(27)$ & & $1658(41)$ \\
\hline
\end{tabular}

*Values are the number (\%).

†Response status according to EULAR response criteria. If change of DMARD at follow-up visit=non-responder.

RA, rheumatoid arthritis.

AITD and change in RA disease activity between baseline and $3 / 6$ months

Comparing baseline and 3 months, patients with (vs without) AITD had a more pronounced decrease in patients global (-28 vs -24$)$, whereas the decrease in pain, HAQ and other DAS28 components was similar (table 4). The change in DAS28 components is displayed in figure 1. Comparing baseline and 6 months, there were only small numerical differences, for all parameters under study (table 4). When adjusting also for the baseline value of the parameter under study, the difference in delta patients global for those with versus without AITD disappeared, but for all other parameters, the pattern of small differences remained (online appendix table II).

In analyses stratified by age at RA diagnosis, the ten or so percent of all patients who were below 45 years of age displayed a somewhat different pattern, with AITD linked to a slightly lower disease activity at baseline, though none of these differences reaches statistical significance (online appendix tables III and IV).

Table 3 DAS28 parameters at baseline and at 3-month follow-up visit for RA patients in the Swedish Rheumatology Quality Register (SRQ), 2006-2016

\section{Patients with complete information at 3-month follow-up visit ( $n=4$ 831)}

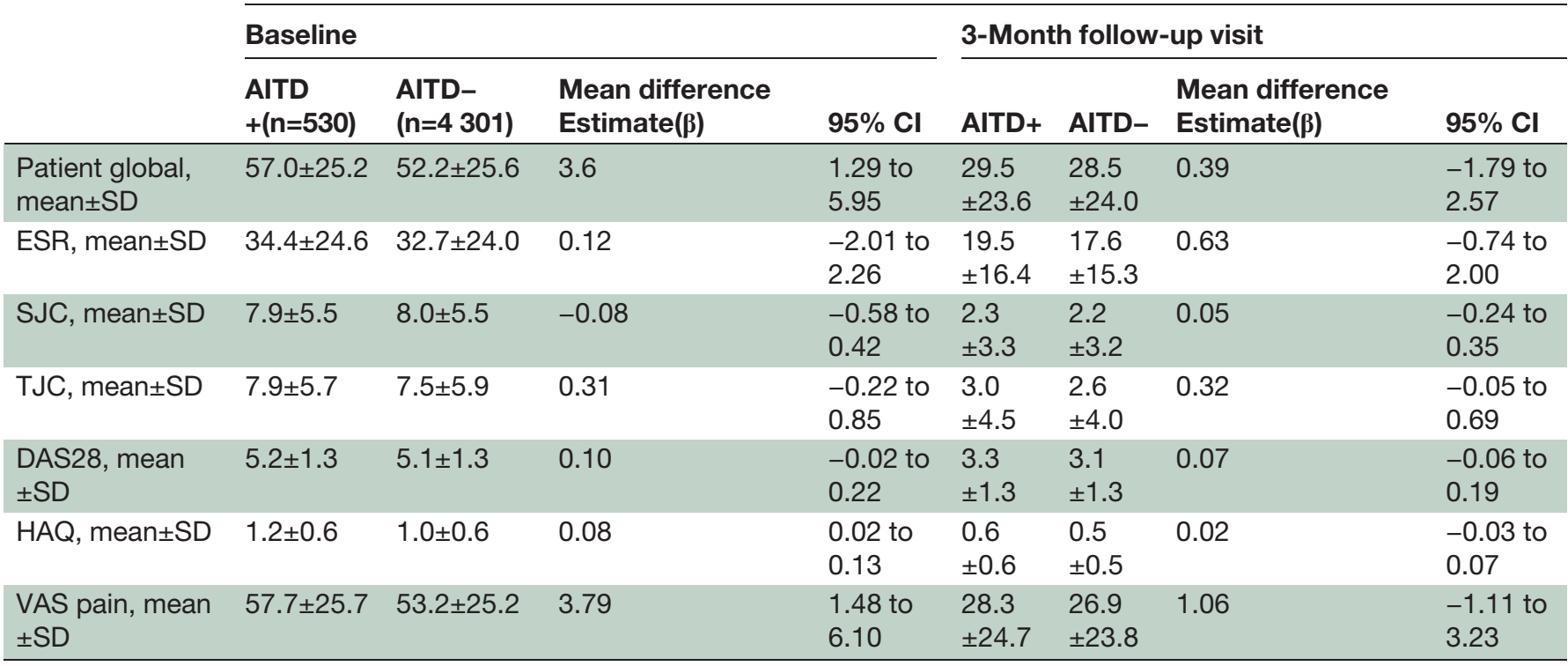

For each of the seven variables named in the first column and for each time point, the estimate $(\beta)$ was provided by a linear regression model for which the variable in the first column was the dependent variable, AITD the independent variable, and age and sex used as adjustment. The estimate $\beta$ gives the mean difference (given the linear model) between the two types of patients, a positive value meaning that the AITD+ patients have on average a higher value than the AITD- patients.

AITD, autoimmune thyroid disease; DAS28, 28-joint Disease Activity Score; ESR, erythrocyte sedimentation rate; HAQ, Health Assessment Questionnaire; RA, rheumatoid arthritis; SJC, swollen joint count; TJC, tender joint count; VAS, Visual Analogue Scale. 
Table 4 Changes in DAS28 parameters from baseline to 3-month and 6-month follow-up visit, among RA patients in the Swedish Rheumatology Quality Register (SRQ)

Patients with complete information at 3-month follow-up ( $n=4$ 831)
Patient with complete information at 6-month follow-up $(n=4010)$

\begin{tabular}{|c|c|c|c|c|c|c|c|c|c|c|}
\hline & $\begin{array}{l}\text { AITD+ } \\
n=530\end{array}$ & $\begin{array}{l}\text { AITD- } \\
n=4301\end{array}$ & $\begin{array}{l}\text { Mean } \\
\text { difference } \\
\text { Estimate }(\beta)\end{array}$ & $\begin{array}{l}95 \% \\
\mathrm{Cl}\end{array}$ & $P$ value & $\begin{array}{l}\text { AITD+ } \\
n=441\end{array}$ & $\begin{array}{l}\text { AITD- } \\
n=3569\end{array}$ & $\begin{array}{l}\text { Mean } \\
\text { difference } \\
\text { Estimate }(\beta)\end{array}$ & $\begin{array}{l}95 \% \\
\mathrm{Cl}\end{array}$ & $P$ value \\
\hline $\begin{array}{l}\triangle \text { patient } \\
\text { global, mean } \\
\pm \text { SD }\end{array}$ & $\begin{array}{l}27.6 \\
(29.1)\end{array}$ & $\begin{array}{l}23.7 \\
(29.2)\end{array}$ & 3.23 & $\begin{array}{l}0.55 \text { to } \\
5.90\end{array}$ & 0.018 & $\begin{array}{l}22.0 \\
(32.6)\end{array}$ & $\begin{array}{l}20.9 \\
(30.2)\end{array}$ & 0.77 & $\begin{array}{l}-2.31 \\
\text { to } 3.85\end{array}$ & 0.6255 \\
\hline $\begin{array}{l}\Delta \mathrm{ESR} \text {, mean } \\
\pm \mathrm{SD}\end{array}$ & $\begin{array}{l}15.0 \\
(22.1)\end{array}$ & $\begin{array}{l}15.1 \\
(21.1)\end{array}$ & -0.51 & $\begin{array}{l}-2.44 \\
\text { to } 1.42\end{array}$ & 0.6061 & $\begin{array}{l}14.2 \\
(19.5)\end{array}$ & $\begin{array}{l}15.2 \\
(21.7)\end{array}$ & -1.57 & $\begin{array}{l}-3.73 \\
\text { to } 0.58\end{array}$ & 0.1531 \\
\hline $\begin{array}{l}\triangle \mathrm{SJC} \text {, mean } \\
\pm \mathrm{SD}\end{array}$ & $\begin{array}{l}5.6 \\
(5.7)\end{array}$ & $5.8(5.5)$ & -0.13 & $\begin{array}{l}-0.63 \\
\text { to } 0.37\end{array}$ & 0.6143 & $\begin{array}{l}5.9 \\
(6.0)\end{array}$ & $5.9(5.8)$ & -0.02 & $\begin{array}{l}-0.60 \\
\text { to } 0.57\end{array}$ & 0.6255 \\
\hline $\begin{array}{l}\Delta \mathrm{TJC} \text {, mean } \\
\pm \mathrm{SD}\end{array}$ & $\begin{array}{l}4.8 \\
(6.0)\end{array}$ & $4.8(5.9)$ & -0.01 & $\begin{array}{l}-0.55 \\
\text { to } 0.53\end{array}$ & 0.9742 & $\begin{array}{l}4.6 \\
(6.1)\end{array}$ & $4.8(6.0)$ & -0.22 & $\begin{array}{l}-0.83 \\
\text { to } 0.39\end{array}$ & 0.4836 \\
\hline $\begin{array}{l}\triangle \mathrm{DAS} 28 \\
\text { mean } \pm \mathrm{SD}\end{array}$ & $\begin{array}{l}2.0 \\
(1.6)\end{array}$ & $2.0(1.5)$ & 0.04 & $\begin{array}{l}-0.10 \\
\text { to } 0.17\end{array}$ & 0.617 & $\begin{array}{l}1.9 \\
(1.6)\end{array}$ & $2.0(1.6)$ & -0.05 & $\begin{array}{l}-0.21 \\
\text { to } 0.12\end{array}$ & 0.5626 \\
\hline $\begin{array}{l}\triangle \mathrm{HAQ}, \text { mean } \\
\pm \mathrm{SD}\end{array}$ & $\begin{array}{l}0.5 \\
(0.6)\end{array}$ & $0.5(0.6)$ & 0.03 & $\begin{array}{l}0.00 \text { to } \\
0.11\end{array}$ & 0.0410 & $\begin{array}{l}0.5 \\
(0.7)\end{array}$ & $0.5(0.6)$ & 0.04 & $\begin{array}{l}-0.03 \\
\text { to } 0.10\end{array}$ & 0.2322 \\
\hline $\begin{array}{l}\triangle V A S \text { pain, } \\
\text { mean } \pm S D\end{array}$ & $\begin{array}{l}29.4 \\
(32.1)\end{array}$ & $\begin{array}{l}26.3 \\
(29.4)\end{array}$ & 2.60 & $\begin{array}{l}-0.13 \\
\text { to } 5.33\end{array}$ & 0.0624 & $\begin{array}{l}23.8 \\
(33.4)\end{array}$ & $\begin{array}{l}22.9 \\
(30.5)\end{array}$ & 0.85 & $\begin{array}{l}-2.27 \\
\text { to } 3.97\end{array}$ & 0.5932 \\
\hline
\end{tabular}

For each of the seven variables named in the first column and for each time point, the estimate $(\beta)$ was provided by a linear regression model for which the variable in the first column was the dependent variable, AITD the independent variable, and age and sex used as adjustment. The estimate $(\beta)$ shows how differently the two types of patients were evolving between baseline and 3/6 months. For a given variable in the first column, a positive value means that the AITD+ patients have on average evolved (decreased) more than the AITD- patients.

AITD, autoimmune thyroid disease; DAS28, 28-joint Disease Activity Score; ESR, erythrocyte sedimentation rate; HAQ, Health Assessment Questionnaire; RA, rheumatoid arthritis; SJC, swollen joint count; TJC, tender joint count; VAS, Visual Analogue Scale.
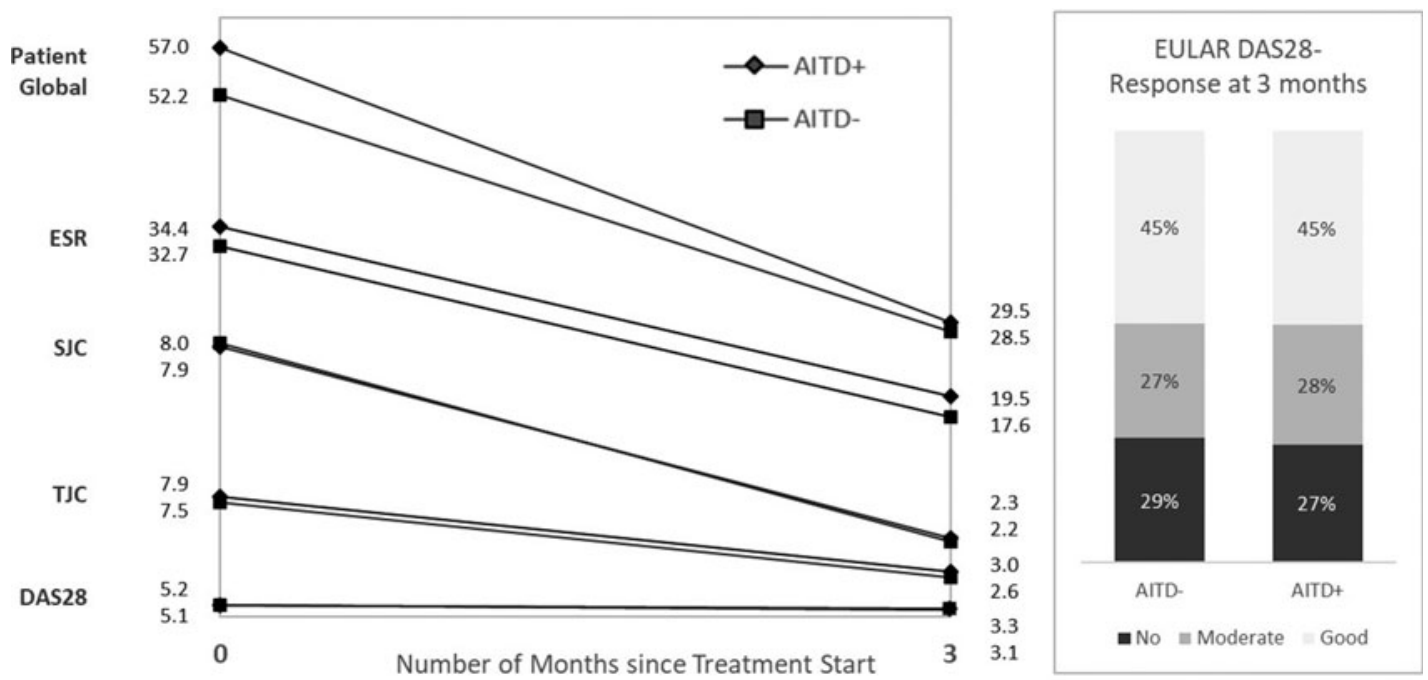

Figure 1 Change in DAS28 components (mean) between 0 and 3 months, and EULAR DAS28-ESR response at 3 months. DAS28-ESR, 28-joint Disease Activity Score-erythrocyte sedimentation rate.

Association between AITD and response to methotrexate as first DMARD in RA

Among 7442 RA patients starting MTX, 6025 had a 3-month follow up-visit and 4996 had a 6-month visit (see online supplementary figure 1). Disease activity measures were registered or imputed (registered for 4 831 and imputed for 1194 patients) at both diagnosis (treatment initiation) and the 3-month follow-up visit. Overall, we observed no difference in the proportion of patients with concurrent AITD among the non/ 
Table 5 Association between autoimmune thyroid disease and response to methotrexate at 3-month follow-up visit among 6025 RA -patients (3 395 non/moderate responders, 2630 good responders) in the Swedish Rheumatology Quality Register (SRQ), imputed dataset

\begin{tabular}{|c|c|c|c|c|}
\hline & $\begin{array}{l}\text { AITD in non } / \text { moderate } \\
\text { responders }(n)^{\star}(\text { cases })\end{array}$ & $\begin{array}{l}\text { AITD in good responders } \\
(n)^{\star} \text { (controls) }\end{array}$ & OR $(95 \% \mathrm{Cl}) \dagger$ & OR $(95 \% \mathrm{Cl}) \ddagger$ \\
\hline Overall & $376(11)$ & $286(11)$ & $0.95(0.80-1.13)$ & $0.93(0.78-1.10)$ \\
\hline \multicolumn{5}{|l|}{ Sex } \\
\hline Women & $336(14)$ & $248(15)$ & $0.93(0.78-1.12)$ & $0.90(0.75-1.08)$ \\
\hline Men & $40(4)$ & $38(4)$ & $1.05(0.66-1.69)$ & $1.03(0.64-1.66)$ \\
\hline \multicolumn{5}{|l|}{ Age group } \\
\hline$<45$ years & $30(9)$ & $17(6)$ & $1.44(0.76-2.76)$ & $1.43(0.74-2.75)$ \\
\hline$\geq 45$ years & $346(11)$ & $269(11)$ & $0.92(0.77-1.10)$ & $0.89(0.75-1.07)$ \\
\hline \multicolumn{5}{|l|}{ Serostatus } \\
\hline RF and/or ACPA positive & $265(11)$ & $192(11)$ & $0.99(0.81-1.22)$ & $0.95(0.78-1.17)$ \\
\hline RF and ACPA negative & $97(10)$ & $81(10)$ & $0.86(0.62-1.20)$ & $0.85(0.60-1.18)$ \\
\hline Serostatatus unspecified & $14(20)$ & $13(16)$ & $1.19(0.50-2.84)$ & $1.49(0.59-3.72)$ \\
\hline
\end{tabular}

*According to EULAR response criteria including imputed values on response status. Values are the numbers (\%).

†Adjusted for age and sex.

$\ddagger$ Adjusted for age, sex, cortisone, HAQ, smoking. Multiple imputations=50.

AITD, autoimmune thyroid disease; HAQ, Health Assessment Questionnaire Disabilitylndex; RA, rheumatoid arthritis.

moderate vs good responders at the 3 -month visit (11\% in both groups, see table 5 ). Separate analyses stratified by sex and seropositivity yielded similar results. Similar results were also observed using the 6-month follow-up visit (online appendix table VI) and when restricted to non-imputed data (online appendix tables V and VII).

Analyses stratified by age (below and above, respectively, 45 years) revealed a trend towards AITD and lower chance of good response among younger patients at 3 months, OR, 1.44; 95\% CI, 0.76 to 2.76 but not in older patients, OR, 0.92; 95\% CI, 0.77 to 1.10 (table 5). At 6 months, there was a significant association between AITD and lack of good response among younger patients (OR 2.75; 95\% CI, 1.04 to 7.28) but not for older patients (OR, 1.11;95\% CI, 0.90 to 1.37 ), online appendix table VI. The lack of good response among young patients was even more pronounced when restricted to non-imputed data (online appendix tables V and VII).

\section{DISCUSSION}

Our results from this large study on the impact of AITD on RA disease presentation and response, indicate that AITD affects disease presentation at RA diagnosis, primarily through patient-reported but not objective measures. Taking this difference into account, AITD did not seem to affect the chance of receiving a good treatment response. These findings underscore the need for a systematic evaluation of not only composite measures such as DAS28 levels but also of its individual components and additional parameters. In contrast to this overall pattern, we noted a somewhat different pattern of disease activity and a stronger negative effect on treatment response, in patients with AITD and below 45 years of age. These latter results extend previous findings of a stronger link between AITD and RA among younger patients (the OR for hypothyroidism in RA patients, 18-44 years of age: 2.12, OR among $45-69$ years: 1.42 , and OR $70+$ years: 1.37$).{ }^{9}$

In light of the age and sex distributions in our study population, the prevalence of AITD of approximately $11 \%$ is in line with previous results. ${ }^{6} 1326$

One prior study, with a different design, has addressed the question whether thyroid dysfunction relates to disease activity in RA. ${ }^{17}$ However, this was a cross-sectional study in established RA using levels of thyroid-stimulating hormone (TSH $>4.2 \mu \mathrm{IU} / \mathrm{mL}$ ) as the exposure, which was present in $38 \%$ of the 52 prevalent RA patients. They found higher disease activity parameters (DAS28 and ESR) in patients with elevated TSH.

Our findings partly corroborate those of Emamifar et al, of 439 RA patients with established RA, who compared disease activity (DAS28-CRP) in RA patients with and without hypothyroidism at treatment initiation. The individual DAS28 components were not evaluated. Treatment response measured as delta DAS28-CRP and DAS28-CRP at 4 months was significantly lower among RA-patients with thyroid disorders. ${ }^{18}$ We extend these findings by demonstrating that they are mainly explained by higher patient-related disease activity parameters at baseline. Differences compared with our study include the study design (patients were not defined as early RA, the treatment was not restricted to methotrexate, thyroid dysfunction was based on hospital records) and the statistical approach.

Several susceptibility genes involved in the pathogenesis of both AITD and RA have been identified, including PTPN22 (protein tyrosine phosphatase nonreceptor type 22), CTLA4 (cytotoxic T-lymphocyteassociated leucocyte antigen) and the HLA gene 
complex including HLA-DRB1 (human leucocyte antigen $\left.\mathrm{DR} \mathrm{B}_{1}\right) .{ }^{1}$ In addition, carriership of different alleles of the HLA-DRB1 locus has been demonstrated to be associated with anti-citrullinated protein antibodies (ACPA)-positivity resulting in a more destructive RA. One hypothesis is that shared susceptibility genes could be one possible explanation to a potential lack of treatment response in the younger $(<45$ years $)$ subgroup of patients. Individuals, who at young adult age have already developed two autoimmune conditions, potentially have a stronger shared inheritance. Patient-reported parameters such as patient global, VAS pain and HAQ could potentially be increased due to symptoms such as fatigue, arthralgia and myalgia of a concurrent AITD. The different patterns in disease activity over time and the lack of treatment response seen in this limited subgroup of younger patients compared with the whole population need to be further investigated.

Our study has some limitations. We did not have information on the presence of thyroid antibodies or TSH levels. Thyroid antibodies have been reported to be around $12 \%$ in the general population while the prevalent of clinically overt AITD has been reported to be lower. ${ }^{27}$ Taking other defined indications into account, thyroxine prescription has been considered an accurate proxy for capturing clinically overt AITD. ${ }^{6}{ }^{22}$ Since we aimed to investigate the impact of clinically overt AITD on RA disease activity and treatment response we found this definition of AITD adequate for our study. It cannot be ruled out that some patients may have a non-autoimmune cause for thyroxine treatment but this risk of a potential misclassification must be viewed as having at most marginal effect on our results. The patients in our study were registered as rheumatoid factor (RF) and/or ACPA positive in the SRQ, but we did not have access to additional information on specific auto-antibody profiles or titres. We did not have information about other comorbidities potentially associated with AITD.

Our study also has some strengths. The large sample size, approximately 9000 included patients compared 52 and 439 in previous studies, allowed us to robustly investigate disease activity and treatment response, also in subgroups. Furthermore, we used prospectively recorded information on prescriptions of thyroxine from the nationwide drug register, irrespective of RA response status, to minimise falsenegative comparisons and the risk of bias due to selective recall, which is especially important in such a common condition. We consider that the large population-based sample size and the clinically relevant definition of AITD make our findings generalisable to early RA patients in an international perspective.
Achievement of disease control within 3-6 months after initiation of RA-treatment has been shown to correlate well with long-term outcome. ${ }^{28}$ Therefore, it is important to identify potential outcome predictors, and common co-morbidities in RA are important candidates, that might capture differences in underlying pathogenic mechanisms, which in turn may relate to clinical disease activity. AITD is of special interest there, since the symptoms of undertreated AITD may overlap with RA symptoms. Based on our results, concomitant AITD only has marginal impact on disease activity and response overall, but RA patients with AITD do have somewhat higher patient reported outcome measures at diagnosis, supporting that measures that may reflect both conditions in a way (patient's global health, pain and function) can be higher in this subgroup, thereby AITD does have an influence on the phenotypic presentation of RA. In turn, this impacts the treatment response criteria used in clinical practice. The interpretation of treatment response should be seen in this light. Thus, when treating and evaluating early RA patients, those $10 \%$ with AITD in particular, it is of importance to pay attention to not only to overall disease activity and response measures such as DAS28 but to unpick its components.

\section{Author affiliations}

${ }^{1}$ Division of Clinical Epidemiology Unit, Department of Medicine, Solna, Karolinska Institutet, Stockholm, Sweden

${ }^{2}$ Karolinska Hospital, Stockholm, Sweden

${ }^{3}$ Faculty of Medicine, University of Iceland School of Health Sciences, Reykjavik, Iceland

Acknowledgements The authors thank all the clinicians and patients registering in the Swedish Rheumatology Quality Register.

Contributors All authors were involved in drafting the article or revising it critically for important intellectual content, and all authors approved the final version to be submitted for publication. KW and JA had full access to all of the data in the study and takes responsibility for the integrity of the data and the accuracy of the data analysis. Study conception and design: KW, JA. Acquisition of data: KW, BD, SS, JA. Analysis and interpretation of data: KW, BD, SS, JA.

Funding This work was supported by research grants from the Swedish Research Council, the Swedish Cancer Society, the Swedish HeartLung Foundation, Nordforsk, Vinnova and FOREUM. Financial support information: Dr Askling has acted or acts as $\mathrm{Pl}$ in agreements between Karolinska Institutet and the following entities, mainly related to the safety monitoring of immunomodulators in rheumatology: Abbvie, BMS, Eli Lilly, Merck, Pfizer, Roche, Samsung Bioepis, Sanofi.

Competing interests None declared.

Patient consent for publication Not required.

Ethics approval The Stockholm Regional Ethics Committee approved this study (DNR 2015/1844-31/2).

Provenance and peer review Not commissioned; externally peer reviewed.

Data availability statement All data relevant to the study are included in the article or uploaded as supplementary information.

Open access This is an open access article distributed in accordance with the Creative Commons Attribution Non Commercial (CC BY-NC 4.0) license, which permits others to distribute, remix, adapt, build upon this work non-commercially, and license their derivative works on different terms, provided the original work is properly cited, appropriate credit is given, any changes made indicated, and the use is non-commercial. See: http://creativecommons.org/licenses/by-nc/4.0/. 
ORCID iD

Kristin Waldenlind http://orcid.org/0000-0002-8701-4434

\section{REFERENCES}

1 Lazurova I, Jochmanova I, Benhatchi K, et al. Autoimmune thyroid disease and rheumatoid arthritis: relationship and the role of genetics. Immunol Res 2014;60:193-200.

2 Raterman HG, van Halm VP, Voskuyl AE, et al. Rheumatoid arthritis is associated with a high prevalence of hypothyroidism that amplifies its cardiovascular risk. Ann Rheum Dis 2008;67:229-32.

3 Chan AT, Al-Saffar Z, Bucknall RC. Thyroid disease in systemic lupus erythematosus and rheumatoid arthritis. Rheumatology (Oxford, England) 2001;40:353-4.

4 Shiroky JB, Cohen M, Ballachey ML, et al. Thyroid dysfunction in rheumatoid arthritis: a controlled prospective survey. Ann Rheum Dis 1993;52:454-6.

5 Bahemuka M, Hodkinson HM. Screening for hypothyroidism in elderly inpatients. Br Med J 1975;2:601-3.

6 Bengtsson C, Padyukov L, Kallberg H, et al. Thyroxin substitution and the risk of developing rheumatoid arthritis; results from the Swedish population-based EIRA study. Ann Rheum Dis 2014;73:1096-100.

7 Pan XF, Gu JQ, Shan ZY. Increased risk of thyroid autoimmunity in rheumatoid arthritis: a systematic review and meta-analysis. Endocrine 2015;50:79-86.

8 Przygodzka M, Filipowicz-Sosnowska A. Prevalence of thyroid diseases and antithyroid antibodies in women with rheumatoid arthritis. Pol Arch Med Wewn 2009;119:39-43.

9 Mahagna H, Caplan A, Watad A, et al. Rheumatoid arthritis and thyroid dysfunction: a cross-sectional study and a review of the literature. Best Pract Res Clin Rheumatol 2018;32:683-91.

10 Becker KL, Ferguson RH, Mc CW. The connective-tissue diseases and symptoms associated with Hashimoto's thyroiditis. N Engl J Med 1963;268:277-80.

11 Boelaert K, Newby PR, Simmonds MJ, et al. Prevalence and relative risk of other autoimmune diseases in subjects with autoimmune thyroid disease. Am J Med 2010;123:183.e1-9.

12 Biro E, Szekanecz Z, Czirjak L, et al. Association of systemic and thyroid autoimmune diseases. Clin Rheumatol 2006;25:240-5.

13 Cardenas Roldan J, Amaya-Amaya J, Castellanos-de la Hoz J, et al. Autoimmune thyroid disease in rheumatoid arthritis: a global perspective. Arthritis. 2012;2012:864907.

14 De Vito P, Incerpi S, Pedersen JZ, et al. Thyroid hormones as modulators of immune activities at the cellular level. Thyroid 2011;21:879-90.

15 Jara EL, Munoz-Durango N, Llanos C, et al. Modulating the function of the immune system by thyroid hormones and thyrotropin. Immunol Lett 2017; 184:76-83.
16 Arnaout MA, Nasrallah NS, el-Khateeb MS. Prevalence of abnormal thyroid function tests in connective tissue disease. Scand $J$ Rheumatol 1994;23:128-32.

17 Joshi P, Agarwal A, Vyas S, et al. Prevalence of hypothyroidism in rheumatoid arthritis and its correlation with disease activity. Trop Doct 2017;47:6-10.

18 Emamifar A, Hangaard J, Jensen Hansen IM. Thyroid disorders in patients with newly diagnosed rheumatoid arthritis is associated with poor initial treatment response evaluated by disease activity score in 28 joints-C-reactive protein (DAS28-CRP): an observational cohort study. Medicine 2017;96:e8357.

19 Waldenlind K, Saevarsdottir S, Bengtsson C, et al. Risk of thyroxine-treated autoimmune thyroid disease associated with disease onset in patients with rheumatoid arthritis. JAMA Netw Open 2018;1: e183567.

20 Arnett FC, Edworthy SM, Bloch DA, et al. The American Rheumatism Association 1987 revised criteria for the classification of rheumatoid arthritis. Arthritis Rheum 1988;31:315-24.

21 Aletaha D, Neogi T, Silman AJ, et al. 2010 rheumatoid arthritis classification criteria: an American College of Rheumatology/European League Against Rheumatism collaborative initiative. Ann Rheum Dis 2010;69:1580-8.

22 Calissendorff J, Ljung R. Thyroxin substitution and open-angle glaucoma: a nationwide register-based study on filled prescriptions. $\mathrm{Br}$ J Ophthalmol 2011;95:592-4.

23 Dayan CM, Daniels GH. Chronic autoimmune thyroiditis. N Engl J Med 1996;335:99-107.

24 Wells G, Becker JC, Teng J, et al. Validation of the 28-joint disease activity score (DAS28) and European league against rheumatism response criteria based on C-reactive protein against disease progression in patients with rheumatoid arthritis, and comparison with the DAS28 based on erythrocyte sedimentation rate. Ann Rheum Dis 2009;68:954-60.

25 Aletaha D, Landewe R, Karonitsch T, et al. Reporting disease activity in clinical trials of patients with rheumatoid arthritis: EULAR/ACR collaborative recommendations. Arthritis Rheum 2008;59:1371-7.

26 Pongratz R, Buchinger W, Semlitsch G, et al. [Increased occurrence of autoimmune thyroiditis in patients with chronic rheumatoid arthritis]. Acta Med Austriaca 2000;27:58-60.

27 Vanderpump MP. The epidemiology of thyroid disease. Br Med Bull 2011:99:39-51.

28 Rezaei H, Saevarsdottir S, Forslind K, et al. In early rheumatoid arthritis, patients with a good initial response to methotrexate have excellent 2-year clinical outcomes, but radiological progression is not fully prevented: data from the methotrexate responders population in the SWEFOT trial. Ann Rheum Dis 2012;71:186-91. 